\title{
A New, Old, and Ancient Conversation Begins
}

\author{
S. Joshua Swamidass (D) \\ https://doi.org/10.54739/9617
}

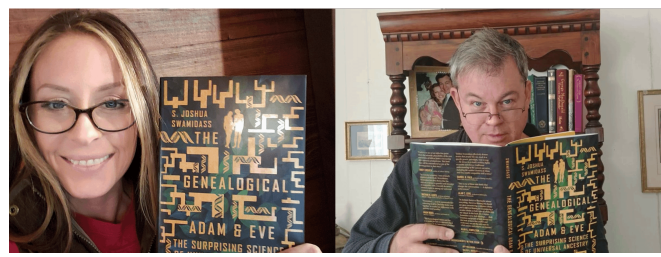

$T_{\text {hes }}$ he Genealogical Adam and Eve will be released on December 10th, and the conversation is beginning anew. This is a new conversation on human origins, but it is also an old conversation, one that brings us to an ancient question. We want to explore how sacred and natural history together might give us a clearer picture of who we are and where we came from.

\section{The Century-Old Conversation}

This book starts a new conversation, but the conversation is connected to an old conversation. Almost exactly 160 years ago, Charles Darwin published Origin of the Species, proposing the his theory of animal and plant evolution. Immediately after its publication, the conversation began about human evolution. All through 1860-1862, widely publicized debates between Thomas Huxley, Robert Owen, and Samuel Wilberforce debated human evolution (see The Great Hippocampus Question), culminating in Huxley's publication of Man's Place in Nature.

It is here, in considering human evolution, where evolution grew into grand cultural conflicts like the Scopes Monkey Trial, scientific racism, and more. It is here, in human origins, where stakes are highest. Ann Gauger recently explained the reason rightly,

\footnotetext{
...the disturbance about evolution - yes, no, theistic, atheistic, guided, unguided, young earth, old earth, Darwinist, near-neutralist, whatever! is about human origins. Where did WE come from? Are we descended from primates or not? And what did God have to do with it?
}

Most readers of Genesis the last few thousand years understood Adam and Eve as ancestors of us all, de novo created without parents, less than 10,000 years ago in the Middle East. Both creationists and evolutions agreed we must choose between this traditional account and evolutionary science. In response, some Christians argued that non-traditional understandings of Adam and Eve could be a faithful response to evolution.

Everyone agreed, in the end, that evolutionary science was in conflict with the traditional de novo account of Adam and Eve. In recent decades, population genetics seemed to establish this conflict as an undeniable fact. As The Genealogical Adam and Eve demonstrates, however, this certainty of conflict was mistaken. We now know that there is a better way forward.

\section{A New Conversation is Growing}

I wrote this book to foster a new conversation, a better conversation than the conflicts of the past. Origins is a quagmire, a wasteland, but we might find virtue here.

\section{Think neither fear nor courage saves us.}

Unnatural vices are fathered by our heroism.

Virtues are forced upon us by our impudent crimes.

These tears are shaken from the wrath-bearing tree

$$
\text { T S. Eliot, “Gerontion" }
$$

The first and last chapters of the book frame the question of Adam and Eve around six virtues. In pursuit of these virtues, we might find a better way through the quagmire of origins. With this image in mind, I chose this inscription for the book.

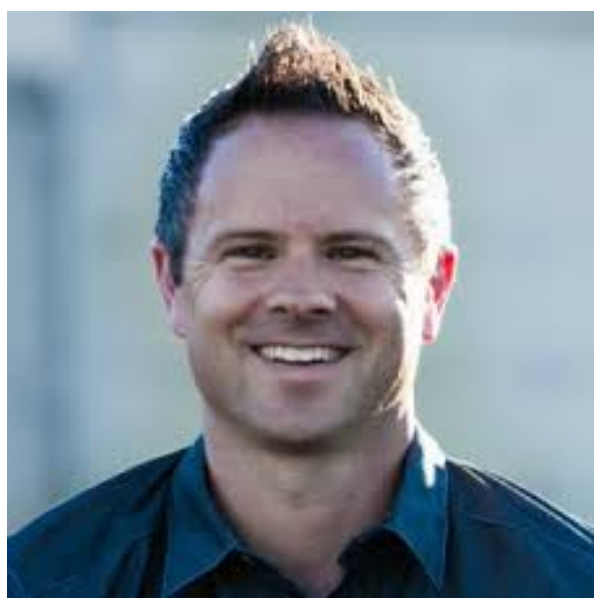

Sean McDowell interviewed Dr Swamidass about his book and the relationship between faith and science, and the book. McDowell writes,

| May this book get the wide readership it deserves. 
Early copies already shipped, and people are posting copies of the book as it arrives. Our stealth book launch in New York with Nathan Lents was a hit (video coming soon!). The publisher is already out of stock, we sold out of the first printing run, and the book is not even released yet. The launch team discount (30\% and free shipping) is valid till December 31st. Hopefully you will get the book without too much of a delay.

We are bracing for the book's release. Much more is on the horizon. We are still forming our plan to inform you of track the media engagement and reviews. To help with this, we may be adding to our team. For now, stay in the loop by joining the book's new facebook group and like its facebook page. We will try and keep you informed there.

While you wait for your copy, there are some free downloads to explore and share with others. IVP generously allowed us to make the first and last chapters of the book available for free. You can download the endorsements too, including a late addition from Jack Collins. The online appendices are also available, with comments from Andrew Torrance, Jack Collins, William Lane Craig, and John Hilber. There will be more to share in the coming months.

\section{Reshuffling The Deck}

A new conversation is growing, you are invited, but the conversation is bigger than any of us. The Genealogical Adam and Eve reshuffles the conversation on origins. Ken Keathley writes that this book “ changes the game."

In the secular world, Nathan Lent's USA Today article was just the beginning. On the release date, December 10th, I will be interviewed on NPR. Other atheists in science already commented on their prerelease impressions, including, Jerry Coyne and Faizal Ali. In a surprising turn, the atheist scientist and humanist Stephen Matheson endorsed the book.

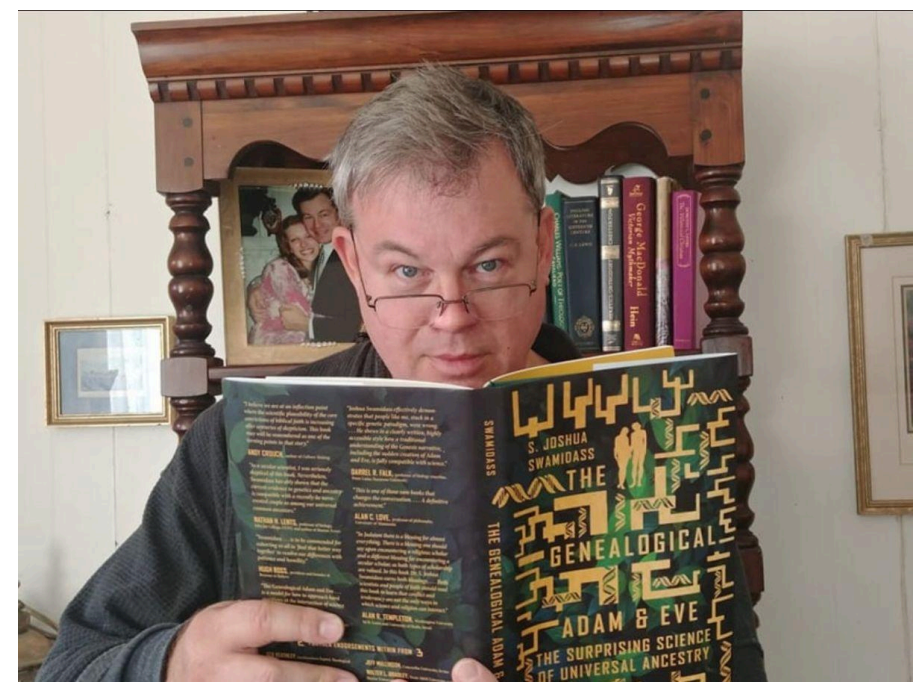

I am looking forward to seeing how the established players adapt, or do not adapt, to the new landscape. BioLogos intends to review the book on their blog. Will they, at long last, make space for "the traditional de novo view of human origins" or will they go a separate way? Reasons to Believe (old earth creationists) are hosting a livestreamed workshop on the book in January too. In February, I will be in a dialogue with Michael Behe in Texas, to discuss Intelligent Design at Texas A\&M. How will these conversations unfold?

The apologetics community has been admirably open-minded. I am impressed. Do not miss this interview by Sean McDowell. This last week, Evan Minton (a Christian that affirms evolutionary science) from Cerebral Faith interviewed me and gave the book a glowing review. The scholar Joe Miller from More Than Cake, also, interviewed me. Soon, Bob Dutko (young earth creationist) is interviewing me about the book on his radio show (listen here on Dec. 2nd, 2019 at $12: 30 \mathrm{pm}$ to $1: 30 \mathrm{pm} \mathrm{CST}$ ).

\section{The Ancient Conversation}

Origins is a quagmire, an ugly argument. I hope this book, The Genealogical Adam and Eve, starts a new conversation where we can find a better way together. A conversation is growing among theologians, exegetes, and thoughtful people in the Church. They are filling in and changing details, making sense of it all together.

This conversation is new, but it is connected to an ancient conversation. In this exchange, we are approaching the grand question together, wondering about who we are and where we came from. All great art and literature bring us here, to this grand question: what does it mean to be human?

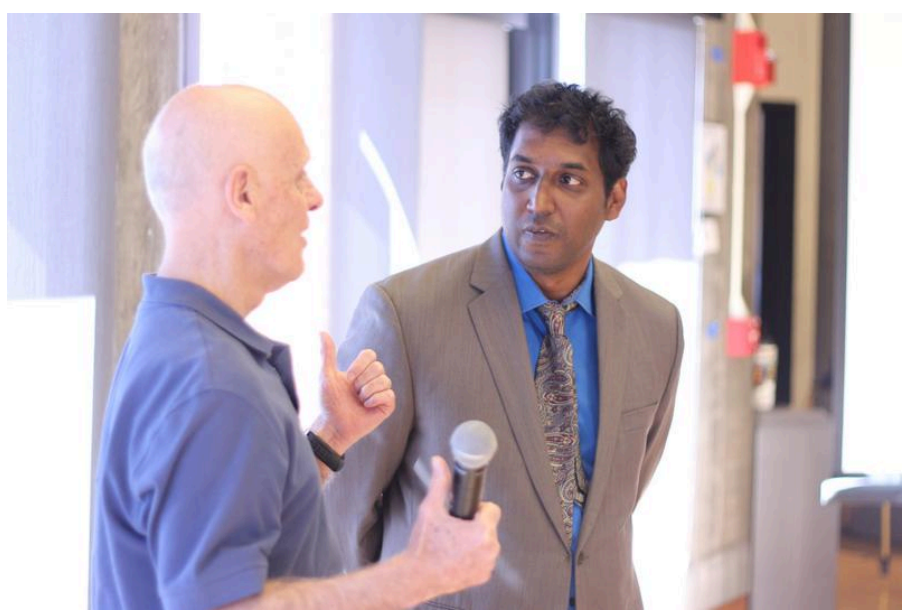

Reasons to Believe is hosting a live-streamed workshop on The Genealogical Adam and Eve in January 2020. include William Lane Craig, Fazale Rana, Andrew Loke, and more. Details to follow.

\title{
References
}

https://peacefulscience.org/books/genealogical-adam-eve/

https://en.wikipedia.org/wiki/Man\%27s_Place_in_Nature

\author{
https:/en.wikipedia.org/wiki/Man\%27s_Place_in_Nature
}


https://evolutionnews.org/2019/11/human-origins-not-a-simplequestion

https://discourse.peacefulscience.org/t/_/5847

https://seanmcdowell.org/blog/are-evolution-and-a-historical-adampossible-a-provocative-model

https://www.patreon.com/posts/49197922

https://discourse.peacefulscience.org/t/_/7049

https://www.facebook.com/groups/peacefulscience

https://www.facebook.com/genealogical.adam.eve

https://www.ivpress.com/the-genealogical-adam-and-eve

https://www.ivpress.com/Media/Default/Downloads/Excerpts-andSamples/5263-Appendixes.pdf

https://peacefulscience.org/articles/lents-in-usa-today/

https://discourse.peacefulscience.org/t/_/8074

https://discourse.peacefulscience.org/t/_/7031 https://discourse.peacefulscience.org/t/_/8017

https://www.facebook.com/groups/genealogical.adam.eve/permalink/ 778118579332336

https://peacefulscience.org/articles/agree-behe/

https://discourse.peacefulscience.org/t/_/8614

https://anchor.fm/evan-minton/episodes/Episode-49-The-

Genealogical-Adam-and-Eve---Interview-With-S--JoshuaSwamidass-e93slk/a-a12b2lq

https://cerebralfaith.net/book-review-the-genealogical-adam-and-eve

https://www.facebook.com/575900232788893/videos/ 488455205093329

https://discourse.peacefulscience.org/t/_/8597

https://wmuz.com

https://peacefulscience.org/articles/human-origins-rtb-workshop/ 